\title{
Predictive Factors for Percutaneous Endoscopic Gastrostomy in Patients with Spontaneous Intracranial Hemorrhage
}

\author{
Ines C. Kiphuth ${ }^{a}$ Joji B. Kuramatsu ${ }^{a}$ Hannes Lücking ${ }^{b}$ Stephan Kloskab \\ Stefan Schwaba Hagen B. Huttner ${ }^{a}$ \\ Departments of a Neurology and ${ }^{\mathrm{b}}$ Neuroradiology, University of Erlangen, Erlangen, Germany
}

\section{Key Words}

Neurocritical care $\cdot$ Intracranial hemorrhage •

Percutaneous endoscopic gastrostomy

\begin{abstract}
Background: Dysphagia is frequent after hemorrhagic stroke, and some of the affected patients require prolonged enteral nutrition, most often via percutaneous endoscopic gastrostomy (PEG) tubes. The identification of patients at risk of prolonged dysphagia permits earlier tube placement and helps guide clinicians in the decision-making process. Methods: This retrospective study included all patients with spontaneous $\mathrm{ICH}$ admitted to a tertiary university hospital from 2007 until 2009 ( $n=208$ ). Fifty-one patients received PEG tubes. PEG tube placement was conducted in ventilated patients within 30 days and in spontaneously breathing patients if swallowing did not improve within 14 days. Results: Twenty-five percent of patients received PEG tubes. Those patients had larger lobar hemorrhages, intraventricular hemorrhage and occlusive hydrocephalus and higher $\mathrm{ICH}$ scores. Furthermore, patients with PEG scored worse on Glasgow Coma Scale (GCS), National Institute of Health Stroke Scale (NIHSS) and Acute Physiology And Chronic Health Evaluation (APACHE II), more frequently needed mechanical ventilation, and had more inflammatory and renal complications. A multivariate regression analysis identified
\end{abstract}

GCS, occlusive hydrocephalus, mechanical ventilation, and systemic sepsis as independent risk factors for PEG tube placement. Conclusion: Disease severity and neurocritical care complications represent the major influencing parameters for PEG tube placement in spontaneous ICH patients.

Copyright $\odot 2010$ S. Karger AG, Basel

\section{Introduction}

Orpharyngeal dysphagia is a disorder of deglutition which frequently occurs after stroke. In light of varying methods of detection and time of assessment the incidence of dysphagia ranges between 29 and $81 \%$ [1-3]. Apart from aspiration, malnutrition is the most severe complication of orpharyngeal dysphagia $[4,5]$. Malnutrition is a common and sometimes unrecognized problem in elderly patients admitted to the hospital [6] and the nutritional status of stroke patients may worsen during hospital stay [4, 7-10]. As poor nutritional status is associated with reduced muscle strength and elevated risk of infection $[11,12]$, which account for increased morbidity and mortality [4, 5, 7, 8,10, 13-15], feeding of dysphagic stroke patients is considered essential. Most patients re-

I.C.K. and J.B.K. contributed equally.

\section{KARGER}

Fax +41613061234 E-Mail karger@karger.ch www.karger.com
(C) 2010 S. Karger AG, Base

0014-3022/11/0651-0032\$38.00/0

Accessible online at:

www.karger.com/ene
Dr. med. Ines Christine Kiphuth

Department of Neurology, University of Erlangen

Schwabachanlage 6, DE-91054 Erlangen (Germany)

Tel. +49 913185 34509, Fax +4991318534510

E-Mail ines-christine.kiphuth@uk-erlangen.de 
cover from dysphagia within a week [16, 17]. However, dysphagia persists in some patients $[1,18,19]$. In order to maintain sufficient hydration and nutrition in those patients, (par-)enteral feeding is essential, and percutaneous endoscopic gastrostomy (PEG) placement in stroke patients is typically performed if patients are unable to take food orally for an extended period of time while their gastrointestinal tract works [20].

In this retrospective study, we analyzed how routine PEG placement in a large tertiary University hospital is performed and identified early predictors for the placement of PEG tubes in patients with intracranial hemorrhage (ICH) in order to guide clinicians in the decisionmaking process.

\section{Methods}

\section{Patient Selection}

All consecutive patients with spontaneous $\mathrm{ICH}$ who were admitted either to the neurocritical care or stroke unit of the Department of Neurology, University of Erlangen, from January 2007 until February 2009 were included into this retrospective analysis. The study was based on a prospectively organized database into which clinical and neuroradiological data of all patients with ICH were included.

Two-hundred and thirty-six patients with the diagnosis of spontaneous ICH were admitted. We did not include patients with secondary $\mathrm{ICH}$, i.e. $\mathrm{ICH}$ related to oral anticoagulant therapy, trauma, tumor, arteriovenous malformations, central venous thrombosis, subarachnoid hemorrhage, or ICH associated with acute thrombolysis or coagulopathy with platelet counts below $50,000 / \mu \mathrm{l}$, nor did we include patients with pre-existing swallowing disorders. Moreover, we excluded those patients who received 'do not treat' or 'do not resuscitate' orders within $72 \mathrm{~h}$ of admission $(n=14)$. Patients who were discharged for rehabilitation without receiving a PEG beforehand were followed until day 60 after the initial event to obtain information on whether PEG tubes had been placed after discharge from our hospital. No patients were lost to follow-up until day 61 . Hence, 208 patients remained eligible for this analysis.

\section{Acquisition of Clinical Parameters and Neuroradiological}

Data

Clinical Presentation. All clinical parameter that were collected during hospital stay (GCS, NIHSS, ICH score, APACHE II score, body temperature, and mean arterial blood pressure) were obtained by reviewing the patient's medical charts, emergency protocols, and institutional databases.

Laboratory Parameters. Laboratory data (such as white blood cells, C-reactive protein etc.) were obtained by reviewing institutional databases. Categorization of data was performed - if necessary - according to institutional laboratory threshold values.

Pre-Admission Status and Past Medical History. Clinical status as well as medical history prior to admission was obtained by mailed standardized questionnaires. If the questionnaire did not return within 6 weeks, a semiquantitative phone interview was conducted with the patient, or the closest relatives, respectively. The telephone interviews were performed by two physicians (I.C.K. and J.B.K.) who were trained and certified for data acquisition on disability and quality of life. The collected data comprised prehospital body mass index, modified Rankin scale, history of ischemic or hemorrhagic stroke, use of nicotine, alcohol abuse (defined as $>80 \mathrm{~g}$ ethanol/day), diagnosis of hypercholesterolemia (defined as $>200 \mathrm{mg} / \mathrm{dl}$ ), diagnosis of arterial hypertension (defined as $>140 / 90 \mathrm{~mm} \mathrm{Hg}$ ), diagnosis of atrial fibrillation, prior myocardial infarction and diagnosis of diabetes mellitus (defined as HbAlc $>6.5 \%$ or fasting plasma glucose $>125 \mathrm{mg} / \mathrm{dl}$ ). All patients or their relatives consented to the anonymous use of the data.

In-Hospital Treatment. These parameters [need and duration of ventilation, external ventricular drainage (EVD; for occlusive hydrocephalus [21]), or lumbar drainages (for posthemorrhagic communicating hydrocephalus [22]), respectively, intraventricular fibrinolysis [22], diagnosis of pneumonia, and sepsis, respectively, $[23,24]]$ were obtained by reviewing the patient's medical charts.

Outcome Findings. Primary outcome was defined as PEG placement within hospital stay or during rehabilitation until day 60 .

Neuroradiologic Data. Diagnosis of ICH was made immediately after hospital admission by either CT (SIEMENS Somatom Volume zoom, Erlangen, Germany) or MRI (Siemens Sonata, 1.5 Tesla, Erlangen, Germany). The site of hemorrhage was defined as either lobar, deep (including thalamic hematomas), cerebellar or brainstem. Hematoma volume was calculated according to the formula of ellipsoids ( $\mathrm{ABC} / 2)$, which has been shown to estimate hemorrhage volume reliably [25]. Intraventricular hemorrhage (IVH) or subdural extensions were not taken into account for volume measurement. IVH was documented and scored using the Graeb score summation for each ventricle [26]. Hematoma growth was defined as an increase of intraparenchymal hemorrhage volume $>33 \%$ as measured by image analysis on the follow-up CT or MRI $24 \mathrm{~h}$ after the baseline scan [27].

\section{Clinical Management}

All patients received standard medical treatment according to national and international guidelines [28]. Patients requiring mechanical ventilation during the course of the treatment were sedated with midazolam and fentanyl. Extraventricular drainage (EVD) was initiated in all patients showing evidence of occlusive hydrocephalus [22]. Pneumonia was diagnosed according to the criteria recommended by the American Thoracic Society [29]. Sepsis was diagnosed and treated according to national and international guidelines [30-32]. Acute kidney injury (AKI) was defined and treated according to the RIFLE classification for critically ill patients $[33,34]$.

\section{PEG Tube Placement}

In ventilated $\mathrm{ICH}$ patients enteral nutrition was started within $24 \mathrm{~h}$ after admission via nasogastric tubes according to international and national guidelines [35-39], or, as soon as further invasive procedures (e.g. delayed EVD placement or hematoma evacuation) had been carried out, respectively. PEG tube placement was initiated once it became apparent that the individual patient would not be able to consume sufficient oral intake to meet long-term metabolic demands within 30 days, but not earlier than 10 days after the initial event $[20,36,40,41]$. The actual placement of the PEG tube was then accomplished within 3 days. 
Table 1. Demographic data, past medical history, and neuroradiologic characteristics of the analyzed ICH patients

\begin{tabular}{|c|c|c|c|}
\hline & $\begin{array}{l}\text { With PEG } \\
(\mathrm{n}=51)\end{array}$ & $\begin{array}{l}\text { Without PEG } \\
(\mathrm{n}=157)\end{array}$ & $\begin{array}{l}\mathrm{p} \text { value } \\
(\mathrm{p}<0.05)\end{array}$ \\
\hline Age, median (IQR) & $71(58-79)$ & $70(61-78)$ & 0.920 \\
\hline Female sex, n (\%) & $22(43.1)$ & $76(48.4)$ & 0.284 \\
\hline \multicolumn{4}{|l|}{ Pre-admission status } \\
\hline $\mathrm{mRS} \leq 2, \mathrm{n}(\%)$ & $34(66.7)$ & $117(74.5)$ & 0.180 \\
\hline Overweight (BMI $\geq 25), \mathrm{n}(\%)$ & $24(47.1)$ & $76(48.4)$ & 0.498 \\
\hline Nicotine abuse, $\mathrm{n}(\%)$ & $16(31.4)$ & $52(33.1)$ & 0.480 \\
\hline Alcohol abuse ( $\geq 80$ g/day), n (\%) & $11(21.6)$ & $33(21.0)$ & 0.538 \\
\hline \multicolumn{4}{|l|}{ Past medical history } \\
\hline Hypertension, n (\%) & $29(56.9)$ & $103(65.6)$ & 0.169 \\
\hline Diabetes mellitus, n (\%) & $12(23.5)$ & $24(15.3)$ & 0.128 \\
\hline Hypercholesterolemia, n (\%) & $11(21.6)$ & $48(30.6)$ & 0.144 \\
\hline Atrial fibrillation, $\mathrm{n}(\%)$ & $5(9.8)$ & $6(3.8)$ & 0.101 \\
\hline Hemorrhagic stroke, n (\%) & $5(9.8)$ & $16(10.2)$ & 0.588 \\
\hline Ischemic stroke, $\mathrm{n}(\%)$ & $13(25.5)$ & $26(16.6)$ & 0.114 \\
\hline Prior cardiac infarction, $\mathrm{n}(\%)$ & $6(11.8)$ & $13(8.3)$ & 0.309 \\
\hline \multicolumn{4}{|l|}{ Neuroradiologic data } \\
\hline \multicolumn{4}{|l|}{ Localization } \\
\hline Lobar, n (\%) & $17(33.3)$ & $63(40.1)$ & 0.243 \\
\hline Lobar volume (ml), median (IQR) & $34.8(7.4-55.3)$ & $16.8(4.9-50.2)$ & 0.047 \\
\hline Deep, n (\%) & $29(56.9)$ & $76(48.4)$ & 0.209 \\
\hline Deep volume (ml), median (IQR) & $20.4(4.6-41.1)$ & $14.9(5.7-36.6)$ & 0.121 \\
\hline Cerebellar, n (\%) & $1(2.0)$ & $9(5.7)$ & 0.248 \\
\hline Cerebellar volume (ml), median (IQR) & $16.3(5.1-31.8)$ & $12.4(4.2-29.2)$ & 0.543 \\
\hline Brainstem, n (\%) & $4(7.8)$ & $9(5.7)$ & 0.399 \\
\hline Brainstem volume (ml), median (IQR) & $10.4(2.7-16.3)$ & $8.7(3.7-14.1)$ & 0.081 \\
\hline Hematoma growth within $24 \mathrm{~h}, \mathrm{n}(\%)$ & $6(11.8)$ & $15(9.6)$ & 0.412 \\
\hline Intraventricular hemorrhage, $\mathrm{n}(\%)$ & $32(62.7)$ & $71(45.2)$ & 0.022 \\
\hline Occlusive hydrocephalus/EVD, n (\%) & $21(41.2)$ & $38(24.2)$ & 0.017 \\
\hline Graeb score, median (IQR) & $4(0-8)$ & $0(0-6)$ & 0.062 \\
\hline ICH score, median (IQR) & $3(2-3)$ & $2(0-3)$ & 0.001 \\
\hline
\end{tabular}

Data are calculated as continuous or categorizes variables and are presented dichotomized for patients with or without PEG tube placement. Significant parameters are expressed in bold.

All spontaneously breathing patients underwent clinical swallowing evaluation by a speech therapist within $24 \mathrm{~h}$ after admission. If aspiration was assumed because of pathological water swallowing tests [42-45], fiberoptic endoscopic evaluation of swallowing was performed [46-51]. Patients with aspiration were monitored for at least fourteen days. Dysphagic patients were routinely reevaluated on a daily basis, or at least every second day, as appropriate. If swallowing did not improve until day 14 after admission, PEG tube placement was initiated within the next 3 days [40, 52].

Because of varying capacity of rehabilitation institutions, some patients were transferred to rehabilitation within 2 weeks after admission. These patients were followed up until day 60 after the initial hospital admission (telephone interviews by I.C.K. and J.B.K.), and potential PEG tube placement during rehabilitation was recorded.

\section{Statistical Analysis}

Statistical analysis was performed with the SPSS 17.0 software package. The significance level was set at $\alpha=0.05$. Statistical tests were two-sided. Distribution of the data was assessed with the Kolmogorov-Smirnov test. Normally distributed data is presented as mean \pm SD and was compared using the Student's t test. Other data are presented as median with IQR (25-75th percentiles), or total range, respectively, and was compared using the Mann-Whitney U test. Pearson $\chi^{2}$ or Fisher's exact tests were used for comparison of frequency distributions of categorized variables between the two groups (PEG vs. no PEG). One stepwise forward multivariate logistic regression analysis (that included all variables with $\mathrm{p}<0.5$ ) was carried out. 
Table 2. Clinical parameters and laboratory findings at admission and during hospital stay

\begin{tabular}{|c|c|c|c|}
\hline & $\begin{array}{l}\text { With PEG } \\
(\mathrm{n}=51)\end{array}$ & $\begin{array}{l}\text { Without PEG } \\
(\mathrm{n}=157)\end{array}$ & $\begin{array}{l}\mathrm{p} \text { value } \\
(\mathrm{p}<0.05)\end{array}$ \\
\hline \multicolumn{4}{|l|}{ Clinical parameters at admission } \\
\hline Body temperature $\left({ }^{\circ} \mathrm{C}\right)$, median (IQR) & $36.6(36.2-37.3)$ & $36.9(36.2-37.4)$ & 0.439 \\
\hline GCS, median (IQR) & $5(3-10)$ & $13(3-15)$ & $<0.001$ \\
\hline NIHSS, median (IQR) & $21(18-38)$ & $10(5-28)$ & $<0.001$ \\
\hline APACHE II score, median (IQR) & $19(16-25)$ & $13(8-21)$ & $<0.001$ \\
\hline Mean arterial pressure (mm Hg), median (IQR) & $123.3(93.3-140)$ & $113.3(100-130)$ & 0.881 \\
\hline \multicolumn{4}{|l|}{ Characteristics during stay } \\
\hline Mechanical ventilation, $\mathrm{n}(\%)$ & $35(68.6)$ & $69(43.9)$ & 0.002 \\
\hline Duration of ventilation (days), median (IQR) & $5(0-27)$ & $0(0-6)$ & 0.012 \\
\hline Hospital stay duration (days), median (IQR) & $16(10-29)$ & $12(6-9)$ & 0.051 \\
\hline Pneumonia, n (\%) & $42(82.4)$ & $70(44.6)$ & $<0.001$ \\
\hline Sepsis, n (\%) & $23(45.1)$ & $16(10.2)$ & $<0.001$ \\
\hline ICP > 20 mm Hg, n (\%) & $2(3.9)$ & $6(3.8)$ & 0.625 \\
\hline \multicolumn{4}{|l|}{ Blood parameters at $72 \mathrm{~h}$} \\
\hline White blood cells $>12 \times 10^{9} / \mathrm{l}, \mathrm{n}(\%)$ & $44(86.3)$ & $57(36.3)$ & $<0.001$ \\
\hline $\mathrm{CRP}$ at $72 \mathrm{~h}(\mathrm{mg} / \mathrm{l})$, mean $\pm \mathrm{SD}$ (range) & $117.9 \pm 86.3(0-308)$ & $74.1 \pm 69.9(0-272)$ & 0.004 \\
\hline $\mathrm{HbA} 1 \mathrm{c}>6.5 \%, \mathrm{n}(\%)$ & $4(7.8)$ & $16(10.2)$ & 0.428 \\
\hline Acute renal failure, $\mathrm{n}(\%)$ & $28(54.9)$ & $50(31.8)$ & 0.003 \\
\hline
\end{tabular}

Significant parameters are expressed in bold.

\section{Results}

The initial screening showed dysphagia or inability to swallow due to mechanical ventilation in 129 patients. Twenty-four spontaneously breathing and all ventilated patients received nasogastric tubes. One ventilated patient died after PEG tube placement due to pulmonary complications.

Overall, 51 of $208 \mathrm{ICH}$ patients (24.5\%) received PEG tube placement. Thirty-one patients received PEG before hospital discharge and another 20 patients during rehabilitation. Of the 31 patients with PEG tube placement during hospital stay the mean duration until PEG tube placement was 17 days (range 15-22) in spontaneously breathing patients, and 18 days (range 13-28) in ventilated patients, respectively. Of the 20 patients who did not receive $\mathrm{PEG}$ tube placement before rehabilitation the mean duration until PEG tube placement was 31.5 days (range 21-48) in spontaneously breathing patients, and 30 days (range 16-51) in ventilated patients, respectively.

Table 1 provides information on demographic characteristics and past medical history. There were no significant differences between patients with and without PEG tube placement. When focusing on neuroradiological pa- rameters, patients who received PEG placement showed significantly larger lobar hematomas, more frequent intraventricular hemorrhage and occlusive hydrocephalus, and an overall higher ICH score, as compared to patients without PEG placement (table 1).

The initial clinical presentation as well as parameters of the clinical course of all analyzed patients is given in table 2. Patients who received PEG tube placement were significantly more severely affected scoring worse on GCS, NIHSS, and APACHE. Moreover, necessity of mechanical ventilation, as well as its duration, was more frequently observed in those patients who received PEG tube placement. Furthermore, inflammatory serum markers and presence of pneumonia and sepsis, as well as occurrence of acute renal failure complicated the clinical course in patients with PEG tube placement significantly more often (table 2).

Table 3 shows the univariate analysis. All significant parameters were adjusted in the multivariate analysis that is given in table 4 . The parameters (1) occlusive hydrocephalus, (2) GCS on admission, (3) necessity of mechanical ventilation, and (4) occurrence of systemic sepsis were independently predisposing for PEG tube placement. 
Table 3. Univariate regression analysis for identification of parameters which were associated with PEG tube placement

\begin{tabular}{|c|c|c|c|}
\hline & OR & $95 \% \mathrm{CI}$ & $\begin{array}{l}\mathrm{p} \\
\text { value }\end{array}$ \\
\hline \multicolumn{4}{|l|}{ Demographic data } \\
\hline Age & 1.026 & $0.967-1.132$ & 0.9323 \\
\hline Female & 0.861 & $0.400-1.853$ & 0.7025 \\
\hline Prior $\mathrm{mRS} \leq 2$ & 1.125 & $0.211-1.304$ & 0.1651 \\
\hline Prior $\mathrm{BMI} \geq 25$ & 0.966 & $0.886-1.052$ & 0.4251 \\
\hline Prior hemorrhagic stroke & 0.897 & $0.249-3.232$ & 0.8677 \\
\hline Prior ischemic stroke & 2.018 & $0.846-4.814$ & 0.1136 \\
\hline Prior cardiac event & 1.175 & $0.054-6.962$ & 0.5261 \\
\hline \multicolumn{4}{|l|}{ Neuroradiologic data } \\
\hline \multicolumn{4}{|l|}{ Localization } \\
\hline Lobar volume & 1.385 & $1.001-1.842$ & 0.0361 \\
\hline Deep volume & 1.223 & $0.601-1.268$ & 0.4754 \\
\hline Cerebellar volume & 0.999 & $0.984-1.014$ & 0.9122 \\
\hline Brainstem volume & 1.809 & $1.000-2.075$ & 0.0419 \\
\hline Hematoma growth within $24 \mathrm{~h}$ & 1.945 & $0.570-6.640$ & 0.2848 \\
\hline Intraventricular hemorrhage & 2.199 & $1.012-5.042$ & 0.0149 \\
\hline Occlusive hydrocephalus & 2.247 & $1.438-4.849$ & 0.0027 \\
\hline Graeb score & 1.565 & $0.498-2.763$ & 0.8422 \\
\hline ICH score & 8.938 & $5.593-12.372$ & 0.0138 \\
\hline \multicolumn{4}{|l|}{ Clinical parameters } \\
\hline \multicolumn{4}{|l|}{ At admission } \\
\hline Body temperature & 1.306 & $0.911-1.872$ & 0.8017 \\
\hline GCS & 0.857 & $0.790-0.931$ & 0.0002 \\
\hline NIHSS & 4.548 & $1.458-6.157$ & 0.0001 \\
\hline APACHE II score & 1.074 & $1.024-1.125$ & 0.0003 \\
\hline Mean arterial pressure & 1.823 & $0.707-4.701$ & 0.2132 \\
\hline \multicolumn{4}{|l|}{ During stay } \\
\hline Mechanical ventilation & 2.439 & $1.744-3.911$ & 0.0391 \\
\hline Duration of ventilation & 1.597 & $0.968-6.485$ & 0.0590 \\
\hline Hospital stay duration & 1.132 & $0.109-1.904$ & 0.1366 \\
\hline Pneumonia & 3.719 & $1.272-4.526$ & 0.0048 \\
\hline Sepsis & 3.645 & $1.746-3.927$ & 0.0027 \\
\hline ICP $>20 \mathrm{~mm} \mathrm{Hg}$ & 1.567 & $0.904-2.945$ & 0.8014 \\
\hline \multicolumn{4}{|l|}{ Blood parameters at $72 \mathrm{~h}$} \\
\hline White blood cells $>12 \times 10^{9} / 1$ & 2.855 & $1.155-5.471$ & 0.0049 \\
\hline $\mathrm{CRP}$ at $72 \mathrm{~h}$ & 2.192 & $1.178-12.701$ & 0.0185 \\
\hline $\mathrm{HbA} 1 \mathrm{c}>6.5 \%$ & 4.347 & $0.336-5.630$ & 0.2601 \\
\hline Acute renal failure & 5.500 & $1.165-25.964$ & 0.0314 \\
\hline
\end{tabular}

Demographic characteristics and past medical history, neuroradiologic data, clinical presentation, and laboratory data were included. Data are calculated as continuous or categorized variables. Significant parameters are expressed in bold.

\section{Discussion}

To the best of our best knowledge, the present study for the first time analyzed the incidence of PEG tube placement in spontaneous ICH patients and compared clinical
Table 4. Multivariate logistic regression model for prediction of PEG tube placement in spontaneous ICH patients

\begin{tabular}{llll}
\hline & OR & $95 \%$ CI & p value \\
\hline Prior mRS $\leq 2$ & 1.013 & $0.872-1.433$ & 0.8876 \\
Prior BMI $\geq 25$ & 0.948 & $0.754-1.651$ & 0.7361 \\
Prior ischemic stroke & 1.875 & $0.948-2.844$ & 0.1479 \\
Lobar volume & 0.879 & $0.784-1.056$ & 0.1385 \\
Deep volume & 1.453 & $0.866-1.678$ & 0.5481 \\
Brainstem volume & 0.854 & $0.301-2.145$ & 0.6947 \\
Occlusive hydrocephalus & $\mathbf{1 . 4 7 1}$ & $\mathbf{0 1 . 8 4}-\mathbf{2 . 6 9 7}$ & $\mathbf{0 . 0 4 8 1}$ \\
GCS & $\mathbf{0 . 9 4 3}$ & $\mathbf{0 . 7 1 2 - 0 . 9 7 9}$ & $\mathbf{0 . 0 0 7 2}$ \\
Hospital stay duration & 1.258 & $0.357-1.945$ & 0.2473 \\
Mechanical ventilation & $\mathbf{1 . 3 9 5}$ & $\mathbf{1 . 0 2 1 - 3 . 1 8 3}$ & $\mathbf{0 . 0 2 8 1}$ \\
Sepsis & $\mathbf{5 . 5 8 4}$ & $\mathbf{2 . 1 7 5 - 1 6 . 5 1 8}$ & $\mathbf{0 . 0 0 1 4}$ \\
HbA1c $>6.5 \%$ & 2.976 & $0.875-4.816$ & 0.3477 \\
Acute renal failure & 2.184 & $0.914-6.491$ & 0.0846 \\
\hline
\end{tabular}

Significant parameters are expressed in bold.

and neuroradiological parameters between patients with and without PEG tube placement. Nearly $25 \%$ of ICH patients require PEG tube placement, and, as a key finding, disease severity (GCS), requirement of mechanical ventilation, presence of occlusive hydrocephalus and occurrence of sepsis were independently related to PEG tube placement. The following aspects emerge from the data.

An incidence of PEG tube placement of nearly $25 \%$ reflects that long-term dysphagia after ICH constitutes a relevant clinical complication [53]. At a second glance, however, and when interpreting the present data, one has to differentiate between ventilated patients who require neurocritical care, and those treated spontaneously on a stroke unit for breathing.

Similar to what has been suggested for ischemic stroke patients in whom mainly disease severity and clinical status - as displayed by the NIHSS - predisposed them for PEG tube placement [54], the baseline prognostic parameters (GCS, hematoma volume, presence of intraventricular hemorrhage and occlusive hydrocephalus [55]) represented the major driving factors necessitating PEG tube placement also in ICH patients who received neurocritical care. Hence, it appears plausible that secondary complications of intensive care medicine such as prolonged requirement of mechanical ventilation [22] or acute renal failure [56-59] were also significantly associated with PEG tube placement. In addition, the incidence of pneumonia (presumably based on aspiration in dysphagic patients), and related systemic sepsis, respectively, was significantly higher in patients who received PEG [54]. This 
may reflect an epiphenomenon that PEG tube placement may have been initiated in such critically ill patients because of these severe systemic complications, rather than because of the disease and its symptoms itself [20].

On the other hand, spontaneously breathing ICH patients on stroke units may have a different risk profile, and probably clinical symptoms (e.g. dysphagia) and site of hemorrhage (e.g. brainstem) may rather represent independent risk factors, as previously suggested in ischemic stroke patients [54]. However, this is still some uncertainty about the timing of PEG tube placement in spontaneously breathing stroke patients $[40,52]$. Besides the fact that lobar hemorrhages with increasing volume predicted PEG tube placement, there was no other hematoma site, and especially not hematoma volume, that was associated with PEG tube placement. On a general note, the incidence of PEG after ICH mainly seems to be related to overall disease severity (and subsequent complications) rather than to specific clinical symptoms alone.

Our study has several shortcomings mainly because of its retrospective design. The specific clinical stroke symptoms were not sufficiently re-assessable. Moreover, a sub- stantial proportion of patients did not receive PEG before rehabilitation because the reason for PEG placement could not be verified as properly as in the clinical setting.

Taken together, disease severity - as expressed by GCS, occlusive hydrocephalus, mechanical ventilation, and sepsis - represents the major influencing factor for PEG tube placement in spontaneous ICH patients. Because of scarce data on the timing and method of enteral feeding in such patients, and until prospective studies will hopefully broaden the knowledge in this stroke field, the present analysis may help to guide stroke physicians in their decision-making process on PEG tube placement in ICH patients.

\section{Acknowledgements}

I.C.K., J.B.K. and H.B.H. designed the study and wrote the manuscript. I.C.K., J.B.K., H.L., and S.K. obtained clinical data by reviewing institutional databases, the patient's medical charts, and imaging data. M.K. and S.S. co-interpreted the data and critically reviewed the manuscript. All authors approved the final version of the manuscript.

\section{References}

1 Barer DH: The natural history and functional consequences of dysphagia after hemispheric stroke. J Neurol Neurosurg Psychiatry 1989;52:236-241.

2 Martino R, Foley N, Bhogal S, Diamant N, Speechley M, Teasell R: Dysphagia after stroke: incidence, diagnosis, and pulmonary complications. Stroke 2005;36:2756-2763.

3 Meng NH, Wang TG, Lien IN: Dysphagia in patients with brainstem stroke: Incidence and outcome. Am J Phys Med Rehabil 2000; 79:170-175.

4 Axelsson K, Asplund K, Norberg A, Alafuzoff I: Nutritional status in patients with acute stroke. Acta Med Scand 1988;224:217224.

5 Choi-Kwon S, Yang YH, Kim EK, Jeon MY, Kim JS: Nutritional status in acute stroke: undernutrition versus overnutrition in different stroke subtypes. Acta Neurol Scand 1998;98:187-192.

6 Dennis M: Nutrition after stroke. Br Med Bull 2000;56:466-475.

7 Davalos A, Ricart W, Gonzalez-Huix F, Soler S, Marrugat J, Molins A, Suner R, Genis D: Effect of malnutrition after acute stroke on clinical outcome. Stroke 1996;27:1028-1032.

8 Gariballa SE, Parker SG, Taub N, Castleden $\mathrm{CM}$ : Influence of nutritional status on clinical outcome after acute stroke. Am J Clin Nutr 1998;68:275-281.
9 Gariballa SE, Parker SG, Taub N, Castleden M: Nutritional status of hospitalized acute stroke patients. Br J Nutr 1998;79:481-487.

10 Unosson M, Ek AC, Bjurulf P, von Schenck $\mathrm{H}$, Larsson J: Feeding dependence and nutritional status after acute stroke. Stroke 1994; 25:366-371.

11 Chandra RK: Graying of the immune system: can nutrient supplements improve immunity in the elderly? JAMA 1997;277:13981399.

12 Fiatarone MA, Evans WJ: The etiology and reversibility of muscle dysfunction in the aged. J Gerontol 1993;48:77-83.

13 Davenport RJ, Dennis MS, Wellwood I, Warlow CP: Complications after acute stroke. Stroke 1996;27:415-420.

14 Poor nutritional status on admission predicts poor outcomes after stroke: observational data from the food trial. Stroke 2003; 34:1450-1456

15 Finestone HM, Greene-Finestone LS, Wilson ES, Teasell RW: Malnutrition in stroke patients on the rehabilitation service and at follow-up: prevalence and predictors. Arch Phys Med Rehabil 1995;76:310-316.

16 Gordon C, Hewer RL, Wade DT: Dysphagia in acute stroke. Br Med J 1987;295:411-414.

17 Robbins J, Levine RL, Maser A, Rosenbek JC, Kempster GB: Swallowing after unilateral stroke of the cerebral cortex. Arch Phys Med Rehabil 1993;74:1295-1300.
18 Mann G, Hankey GJ, Cameron D: Swallowing function after stroke: prognosis and prognostic factors at 6 months. Stroke 1999; 30:744-748.

19 Smithard DG, O’Neill PA, England RE, Park CL, Wyatt R, Martin DF, Morris J: The natural history of dysphagia following a stroke. Dysphagia 1997;12:188-193.

20 Gencosmanoglu R: Percutaneous endoscopic gastrostomy: a safe and effective bridge for enteral nutrition in neurological or non-neurological conditions. Neurocrit Care 2004;1: 309-317.

21 van Gijn J, Hijdra A, Wijdicks EF, Vermeulen $\mathrm{M}$, van Crevel H: Acute hydrocephalus after aneurysmal subarachnoid hemorrhage. J Neurosurg 1985;63:355-362.

22 Huttner HB, Staykov D, Bardutzky J, Nimsky C, Richter G, Doerfler A, Schwab S: Treatment of intraventricular hemorrhage and hydrocephalus. Nervenarzt 2008;79:13691370, 1372-1364, 1376.

23 Tejerina E, Esteban A, Fernandez-Segoviano P, Frutos-Vivar F, Aramburu J, Ballesteros D, Rodriguez-Barbero JM: Accuracy of clinical definitions of ventilator-associated pneumonia: comparison with autopsy findings. J Crit Care 2009;25:62-68. 
24 Muckart DJ, Bhagwanjee S: American College of Chest Physicians/Society of Critical Care Medicine consensus conference definitions of the systemic inflammatory response syndrome and allied disorders in relation to critically injured patients. Crit Care Med 1997;25:1789-1795.

25 Kothari RU, Brott T, Broderick JP, Barsan WG, Sauerbeck LR, Zuccarello M, Khoury J: The ABCs of measuring intracerebral hemorrhage volumes. Stroke 1996;27:1304-1305.

26 Graeb DA, Robertson WD, Lapointe JS, Nugent RA, Harrison PB: Computed tomographic diagnosis of intraventricular hemorrhage: etiology and prognosis. Radiology 1982;143:91-96.

27 Brott T, Broderick J, Kothari R, Barsan W, Tomsick T, Sauerbeck L, Spilker J, Duldner J, Khoury J: Early hemorrhage growth in patients with intracerebral hemorrhage. Stroke 1997;28:1-5.

28 Broderick J, Connolly S, Feldmann E, Hanley D, Kase C, Krieger D, Mayberg M, Morgenstern L, Ogilvy CS, Vespa P, Zuccarello M: Guidelines for the management of spontaneous intracerebral hemorrhage in adults: 2007 update: a guideline from the American Heart Association/American Stroke Association Stroke Council, High Blood Pressure Research Council, and the Quality Of Care and Outcomes in Research Interdisciplinary Working Group. Circulation 2007;116:e391e413.

29 Mandell LA, Wunderink RG, Anzueto A, Bartlett JG, Campbell GD, Dean NC, Dowell SF, File TM Jr, Musher DM, Niederman MS, Torres A, Whitney CG: Infectious Diseases Society of America/American Thoracic Society consensus guidelines on the management of community-acquired pneumonia in adults. Clin Infect Dis 2007;44(suppl 2):S27-S72.

30 Reinhart K, Brunkhorst FM, Bone HG, et al: Prevention, diagnosis, treatment, and follow-up care of sepsis: first revision of the S2K guidelines of the German Sepsis Society (DSG) and the German Interdisciplinary Association for Intensive and Emergency Care Medicine (DIVI)]. Anaesthesist 2010; 59:347-370

31 American College of Chest Physicians/Society of Critical Care Medicine Consensus Conference: Definitions for sepsis and organ failure and guidelines for the use of innovative therapies in sepsis. Crit Care Med 1992; 20:864-874.

32 Dellinger RP, Levy MM, Carlet JM, et al: Surviving sepsis campaign: International guidelines for management of severe sepsis and septic shock: 2008. Crit Care Med 2008;36: 296-327.

33 Bellomo R, Ronco C, Kellum JA, Mehta RL, Palevsky P: Acute renal failure - definition, outcome measures, animal models, fluid therapy and information technology needs: 2nd International Consensus Conference of the Acute Dialysis Quality Initiative (ADQI) group. Crit Care 2004;8:R204-R212.
34 Ronco C, Levin A, Warnock DG, Mehta R, Kellum JA, Shah S, Molitoris BA: Improving outcomes from acute kidney injury (AKI): report on an initiative. Int J Artif Organs 2007;30:373-376.

35 Kreymann KG, Berger MM, Deutz NE, Hiesmayr M, Jolliet P, Kazandjiev G, Nitenberg $G$, van den Berghe G, Wernerman J, Ebner C, Hartl W, Heymann C, Spies C: Espen guidelines on enteral nutrition: Intensive care. Clin Nutr 2006;25:210-223.

36 Volkert D, Berner YN, Berry E, et al: Espen guidelines on enteral nutrition: geriatrics. Clin Nutr 2006;25:330-360.

37 Martin CM, Doig GS, Heyland DK, Morrison T, Sibbald WJ: Multicentre, cluster-randomized clinical trial of algorithms for critical-care enteral and parenteral therapy (ACCEPT). CMAJ 2004;170:197-204.

38 Taylor SJ, Fettes SB, Jewkes C, Nelson RJ: Prospective, randomized, controlled trial to determine the effect of early enhanced enteral nutrition on clinical outcome in mechanically ventilated patients suffering head injury. Crit Care Med 1999;27:2525-2531.

39 Doig GS, Simpson F, Finfer S, Delaney A, Davies AR, Mitchell I, Dobb G: Effect of evidence-based feeding guidelines on mortality of critically ill adults: a cluster randomized controlled trial. JAMA 2008;300:2731-2741.

40 Dennis MS, Lewis SC, Warlow C: Effect of timing and method of enteral tube feeding for dysphagic stroke patients (food): a multicentre randomised controlled trial. Lancet 2005;365:764-772.

41 Schroder O, Hoepffner N, Stein J: Enteral nutrition by endoscopic means. 1 . Techniques, indications, types of enteral feed. Z Gastroenterol 2004;42:1385-1392.

42 DePippo KL, Holas MA, Reding MJ: Validation of the 3-oz water swallow test for aspiration following stroke. Arch Neurol 1992;49: 1259-1261.

43 DePippo KL, Holas MA, Reding MJ: The burke dysphagia screening test: validation of its use in patients with stroke. Arch Phys Med Rehabil 1994;75:1284-1286.

44 Gottlieb D, Kipnis M, Sister E, Vardi Y, Brill S: Validation of the $50 \mathrm{ml}^{3}$ drinking test for evaluation of post-stroke dysphagia. Disabil Rehabil 1996;18:529-532.

45 Hinds NP, Wiles CM: Assessment of swallowing and referral to speech and language therapists in acute stroke. Q J Med 1998;91: 829-835.

46 Dziewas R, Warnecke T, Olenberg S, Teismann I, Zimmermann J, Kramer C, Ritter M, Ringelstein EB, Schabitz WR: Towards a basic endoscopic assessment of swallowing in acute stroke - development and evaluation of a simple dysphagia score. Cerebrovasc Dis 2008;26:41-47.
47 Langmore SE: Evaluation of oropharyngeal dysphagia: which diagnostic tool is superior? Curr Opin Otolaryngol Head Neck Surg 2003;11:485-489.

48 Leder SB, Espinosa JF: Aspiration risk after acute stroke: comparison of clinical examination and fiberoptic endoscopic evaluation of swallowing. Dysphagia 2002;17:214-218.

49 Lim SH, Lieu PK, Phua SY, Seshadri R, Venketasubramanian N, Lee SH, Choo PW: Accuracy of bedside clinical methods compared with fiberoptic endoscopic examination of swallowing (FEES) in determining the risk of aspiration in acute stroke patients. Dysphagia 2001;16:1-6.

50 Warnecke T, Dziewas R, Oelenberg S, Ritter M, Dittrich R, Schabitz WR, Ringelstein EB, Nabavi DG: Serial fiberoptic endoscopic evaluation of swallowing in patients with acute stroke and dysphagia: case report and general considerations. J Stroke Cerebrovasc Dis 2006; $15: 172-175$.

51 Warnecke T, Teismann I, Oelenberg S, Hamacher C, Ringelstein EB, Schabitz WR, Dziewas R: The safety of fiberoptic endoscopic evaluation of swallowing in acute stroke patients. Stroke 2009;40:482-486.

52 Bola KR: Use of percutaneous endoscopic gastrostomy in acute dysphagic stroke. Saudi J Gastroenterol 2001;7:59-61.

53 Bath PMW, Bath FJ, Smithard DG: Interventions for dysphagia in acute stroke (Cochrane review). London, The Cochrane Library, 2002

54 Conway DS, Ranawat NS, Degeorgia M, Alshekhlee A: Predictors of peg tube placement in acute ischemic stroke. AAN Ann Meet, 2009, A158.

55 Diringer MN, Edwards DF, Zazulia AR: Hydrocephalus: A previously unrecognized predictor of poor outcome from supratentorial intracerebral hemorrhage. Stroke 1998; 29:1352-1357.

56 Yokohama S, Aoshima M: Risk factors of early mortality after percutaneous endoscopic gastrostomy: a retrospective study. Nippon Shokakibyo Gakkai Zasshi 2009;106:13131320.

57 Freeman C, Ricevuto A, Delegge MH: Enteral nutrition in patients with dementia and stroke. Curr Opin Gastroenterol 2010;26: 156-159.

58 Higaki F, Yokota O, Ohishi M: Factors predictive of survival after percutaneous endoscopic gastrostomy in the elderly: is dementia really a risk factor? Am J Gastroenterol 2008;103:1011-1016; quiz 1017

59 Nair S, Hertan H, Pitchumoni CS: Hypoalbuminemia is a poor predictor of survival after percutaneous endoscopic gastrostomy in elderly patients with dementia. Am J Gastroenterol 2000;95:133-136. 